\title{
Plasma Adiponectin Levels in Primary Biliary Cirrhosis: A Novel Perspective for Link Between Hypercholesterolemia and Protection Against Atherosclerosis
}

Annarosa Floreani, M.D., ${ }^{1}$ A. Variola, M.D., ${ }^{1}$ G. Niro, M.D., ${ }^{2}$ A. Premoli, M.D., ${ }^{3}$ V. Baldo, M.D., ${ }^{4}$ R. Gambino, M.D., ${ }^{3}$ G. Musso, M.D., ${ }^{3}$ M. Cassader, M.D., ${ }^{3}$ S. Bo, M.D., ${ }^{3}$ F. Ferrara, M.D., ${ }^{1}$ D. Caroli, M.D., ${ }^{1}$ E. Rosa Rizzotto, M.D., ${ }^{1}$ and Marilena Durazzo, M.D. ${ }^{3}$

${ }^{1}$ Department of Surgical and Gastroenterological Sciences, University of Padova, Padova, Italy; ${ }^{2}$ Department of Gastroenterology, Hospital Casa Sollievo della Sofferenza, San Giovanni Rotondo, Italy; ${ }^{3}$ Department of Medicine, Ospedale Molinette, Torino, Italy; and ${ }^{4}$ Department of Environmental Medicine and Public Health, University of Padova, Padova, Italy

INTRODUCTION: Hypercholesterolemia is a common finding in primary biliary cirrhosis (PBC), but the risk of cardiovascular events in PBC patients is not increased in respect to the general population. High serum adiponectin levels appear to play a protective role in the development of either metabolic syndrome or cardiovascular disease.

AIM: $\quad$ To investigate factors potentially preventing atherosclerosis in PBC patients.

METHODS: $\quad$ Circulating levels of adiponectin, resistin, leptin, and tumor necrosis factor-alpha (TNF- $\alpha$ ) were measured in 137 consecutive PBC patients (125 women, 12 men; mean age $61.6 \pm 12.3 \mathrm{yr}$ ), 137 sex- and age-matched healthy controls, and 30 female patients with nonalcoholic steatohepatitis (NASH) and associated metabolic syndrome.

RESULTS: $\quad$ The body mass index (BMI) was comparable in the three groups, whereas total cholesterol was significantly higher in both PBC and NASH cases than in controls $(221.6 \pm 50.5 \mathrm{mg} / \mathrm{dL}$ in PBC vs $221.7 \pm 39.7 \mathrm{mg} / \mathrm{dL}$ in NASH vs $209.8 \pm 39.2 \mathrm{mg} / \mathrm{dL}$ in controls, $P<0.05)$. Serum concentrations of adiponectin, resistin, and leptin were significantly higher in PBC patients than in either NASH cases or controls $(P<0.05)$. Among the PBC patients, only adiponectin correlated positively with histological progression of the disease $(P=0.001)$ and negatively with BMI $(P=0.01)$. Logistic regression analysis revealed that adiponectin correlated independently with age, BMI, Mayo score, and gamma-glutamyl transpeptidase.

CONCLUSIONS: The high adiponectin concentrations observed in PBC patients should be regarded as a possible protective factor against atherogenesis. The search for further protective factors should be encouraged.

(Am J Gastroenterol 2008;103:1959-1965)

\section{INTRODUCTION}

Hypercholesterolemia is a common finding in primary biliary cirrhosis (PBC). It is still debated, however, whether hyperlipidemia increases the cardiovascular risk and should be treated. In a cohort of 312 PBC patients observed for $7.4 \mathrm{yr}$, the incidence of atherosclerotic diseases was not statistically different when compared with age-matched and sex-matched controls (1). In an Italian cohort of $400 \mathrm{PBC}$ patients followed up for $6.2 \mathrm{yr}$, marked hypercholesterolemia, typical of severe long-standing cholestasis, was not associated with any increased risk of vascular disease (2). The same Italian researchers recently conducted ultrasound imaging studies on the carotid artery of $103 \mathrm{PBC}$ patients (38\% of them with hypercholesterolemia), 37 controls with hypercholesterolemia, and 141 matched controls with normal cholesterol. Controls with hypercholesterolemia, but not $\mathrm{PBC}$ patients with high serum cholesterol, had increased risk of intima-media thickness. These results suggest that hypercholesterolemia is not consistently associated with subclinical atherosclerosis in PBC (3), though no putative protective factors have been studied specifically as yet in PBC.

It has recently been claimed that adipose tissue takes a metabolically active part in mediating vascular complications (4). Adipose tissue is a part of the endocrine system and acts as an active endocrine and paracrine organ secreting a 
number of mediators (known as adipokines) involved in various metabolic processes (5). These factors include adiponectin, leptin, resistin, tumor necrosis factor-alpha (TNF- $\alpha$ ), complement components, plasminogen activator inhibitor-1, and proteins of renin-angiotensin system.

Adiponectin is the most abundant of the factors known to be secreted. It is produced by the adipocytes and has several functions. In particular, it acts as an antiatherogenic factor by inhibiting the conversion of macrophages into foam cells, as an antidiabetic factor by increasing insulin sensitivity and reducing gluconeogenesis, and as an anti-inflammatory factor by inhibiting the hepatic synthesis of TNF- $\alpha$ (6). Plasma adiponectin levels have also been shown to correlate with surrogate markers of atherosclerosis. Low plasma adiponectin levels are associated with the progression of subclinical coronary atherosclerosis. Adiponectin also affords protection against atherosclerosis and metabolic syndrome (7). Leptin has several effects on energy homeostasis (8). Although it was initially considered an antiobesity hormone, its primary role is to serve as a metabolic signal of energy sufficiency rather than excess (9). Resistin is a $12 \mathrm{kDa}$ polypeptide that interferes with insulin homeostasis. In vivo treatment with recombinant resistin induces insulin resistance in rodents, whereas immune neutralization of resistin has the opposite effect (10). In vivo studies have suggested an association between high resistin levels and glucose intolerance, hyperinsulinemia, and a limited suppression of fatty acids (11). Finally, TNF- $\alpha$ is a key cytokine involved in several metabolic processes including the repression of genes involved in both glucose metabolism and fatty acid oxidation $(12,13)$. TNF- $\alpha$ and adiponectin interact in various biological systems. These two key mediators control each other's synthesis and activity, thereby ensuring a physiological balance. They may have a key role in diseases associated with insulin resistance in which this critical balance may be impaired, leading to chronic inflammation (14).

The aim of the present study was to investigate factors potentially preventing atherosclerosis in PBC patients.

\section{MATERIAL AND METHODS}

\section{Patients}

The study was conducted on patients being followed up at three Italian referral centers (Padua University, Turin University, and San Giovanni Rotondo Hospital), i.e.,

1. In total, 137 consecutive PBC patients (12 men, 125 women; mean age $61.6 \pm 12.3 \mathrm{yr}$ );

2. In total, 30 consecutive female patients with nonalcoholic steatohepatitis (NASH) with associated metabolic syndrome (mean age $49.9 \pm 3.7 \mathrm{yr}$ ).

One hundred and thirty-seven healthy insulin-sensitive subjects (Homeostasis Model Assessment Score for Insulin Resistance [HOMA-IR] $<2 \mathrm{mmol} / \mathrm{L} \times \mu \mathrm{U} / \mathrm{mL})$, matched for sex and class of age with PBC patients (mean age $60.2 \pm$ $10.4 \mathrm{yr})$, served as controls. The study was approved by the local ethical committee, and all subjects gave their informed consent to their participation in the study.

The diagnosis of PBC was based on an antimitochondrial antibody titer of at least 1:40, abnormal liver function tests, and a diagnostic or compatible liver biopsy. The Mayo score, based on a combination of five variables (bilirubin, age, albumin, prothrombin time, and severity of edema) was calculated for each patient (15). The standard treatment consisted of ursodeoxycholic acid (15 mg/kg/day) in divided doses given after meals.

The diagnosis of NASH was considered in the presence of chronic hypertransaminasemia and bright liver at ultrasound, in the absence of any putative cause of liver disease. The presence of metabolic syndrome was diagnosed according to the Adult Treatment Panel III criterion (16). In all subjects, liver biopsy was diagnostic for NASH, according to Brunt et al. (17), on the basis of the presence of fibrosis (grade 1 or higher) or necroinflammation (grade 2 or higher).

Fasting glucose and insulin levels were used to calculate insulin resistance according to the HOMA technique (18).

\section{Laboratory Analysis}

Serum adiponectin, leptin, and TNF- $\alpha$ were measured by sandwich enzyme-linked immunosorbent assays (R\&D System Europe, Ltd., Abingdon, U.K.). All samples were diluted $1: 100$. For human adiponectin, the kit has a sensitivity of $0.25 \mathrm{pg} / \mathrm{mL}$ in a $50-\mu \mathrm{L}$ sample size and a range of 3.9-250.0 $\mathrm{ng} / \mathrm{mL}$. The intra- and interassay coefficients of variations (CVs) were $3.4 \%$ and $5.8 \%$, respectively.

For human leptin, the kit has a sensitivity of less than $7.8 \mathrm{pg} / \mathrm{mL}$ in a $50-\mu \mathrm{L}$ sample size and a range of $15-1,000$ $\mathrm{pg} / \mathrm{mL}$. The intra- and interassay CVs were $3.0 \%$ and $4.2 \%$, respectively. For TNF- $\alpha$, the kit has a sensitivity of 0.12 $\mathrm{pg} / \mathrm{mL}$ in a $200-\mu \mathrm{L}$ sample size and a range of $0.5-32.0$ $\mathrm{pg} / \mathrm{mL}$. The intra- and interassay CVs were $5.9 \%$ and $12.6 \%$, respectively.

Resistin was measured by a biotin-labeled antibody-based sandwich enzyme immunoassay (Bio Vendor Laboratory Medicine, Inc., Brno, Czech Republic). The intra-assay and interassay CVs were $2.8-3.4 \%$ and 5.5-6.8\%, respectively.

\section{Statistical Analysis}

Data are summarized as frequencies and percentages for categorical data and as means \pm standard deviation (SD) for continuous data. Analyses were performed using the $\chi^{2}$ test or Fisher's exact test, one-way analysis of variance (ANOVA), linear logistic analysis, and Student's $t$-test adjusted for the Bonferroni correction as appropriate. A multivariate logistic regression analysis was conducted in the PBC group to identify variables independently associated with a serum adiponectin level $\geq 1,600 \mu \mathrm{g} / \mathrm{L}$ (75th percentile of the PBC sample). A $P$ value of $\leq 0.05$ was considered significant. The analyses were carried out using the Statistical Package for the Social Sciences (SPSS, Chicago, IL). 


\section{RESULTS}

The clinical and biochemical details of patients are listed in Table 1. Body mass index (BMI) was comparable in all groups. Total cholesterol was significantly higher in both PBC and NASH patients than in controls $(221.6 \pm 50.5 \mathrm{mg} / \mathrm{dL}$ in $\mathrm{PBC} v s 221.7 \pm 39.7$ in NASH $v s 209.8 \pm 39.2$ in controls, $P<0.05)$.

Figure 1 shows the serum concentrations of adiponectin, resistin, leptin, and TNF- $\alpha$ expressed as mean \pm SD in the study groups and healthy controls. Adiponectin was significantly higher in PBC patients compared to either NASH patients or controls $(14,338 \pm 12,221 \mathrm{ng} / \mathrm{mL}$ vs $6,941 \pm$ $4,386 \mathrm{ng} / \mathrm{mL}$ vs 7,092 $\pm 4,637 \mathrm{ng} / \mathrm{mL}, P<0.02)$. Serum adiponectin levels were similar in NASH patients and in controls $(P=\mathrm{NS})$. Serum leptin was significantly higher in PBC patients than in controls $(17,411 \pm 17,936 \mathrm{ng} / \mathrm{mL}$ vs 8,177 $\pm 10,222 \mathrm{ng} / \mathrm{mL}, P<0.05)$, whereas no significant difference emerged in the leptin serum concentrations between $\mathrm{PBC}$ and NASH patients. Serum resistin was significantly higher in PBC patients than in either NASH patients or controls $(7.28 \pm 4.70 \mathrm{ng} / \mathrm{mL}$ vs $3.30 \pm 1.21 \mathrm{ng} / \mathrm{mL}$ vs $3.45 \pm$ $1.22 \mathrm{ng} / \mathrm{mL}, P<0.05)$, whereas no significant difference in serum resistin levels was found between NASH patients and controls $(P=\mathrm{NS})$. Serum TNF- $\alpha$ was slightly increased in PBC patients, but there was no significant difference among the three groups.

Comparing the NASH subjects with a group of $30 \mathrm{PBC}$ patients (selected from the 137 PBC study group) matched for age, sex, and degree of liver fibrosis, the serum levels of adiponectin and resistin were significantly higher in $\mathrm{PBC}$ than in NASH patients, whereas no significant difference was

Table 1. Clinical Details of the Study Groups (Biochemical Parameters Are Expressed as Mean $\pm \mathrm{SD}$ )

\begin{tabular}{lccc}
\hline & PBC & NASH & $P$ Value \\
\hline Number & 137 & 30 & \\
Age (yr) & $61.6 \pm 12.3$ & $49.9 \pm 3.7$ & $<0.001$ \\
M/F & $12 / 125$ & $0 / 30$ & NS \\
BMI & $25.1 \pm 4.5$ & $24.5 \pm 2.8$ & NS \\
AST (U/L) & $49.1 \pm 29.6$ & $32.9 \pm 13.1$ & NS \\
ALT (U/L) & $53.3 \pm 36.8$ & $66.3 \pm 15.8$ & NS \\
GGT (U/L) & $129.6 \pm 121.6$ & $86.9 \pm 14.8$ & NS \\
ALP (U/L) & $335.1 \pm 302.6$ & $86.6 \pm 33.3$ & $<0.001$ \\
Total bilirubin $(\mu$ mol/L) & $0.78 \pm 0.63$ & $0.88 \pm 0.31$ & NS \\
Cholesterol (mg/dL) & $221.6 \pm 50.5$ & $221.7 \pm 39.7$ & NS \\
Triglycerides (mg/dL) & $115.9 \pm 40.8$ & $146.2 \pm 79.1$ & 0.03 \\
Glucose (mg/dL) & $101.4 \pm 42.2$ & $82.2 \pm 7.7$ & NS \\
Histological stage & & & \\
I & 30 & - & \\
II & 55 & 20 & \\
III & 36 & 10 & \\
IV & 16 & - & \\
\hline
\end{tabular}

Normal values: AST (aspartic aminotransferase) <35 U/L; ALT (alanine aminotransferase) $<40 \mathrm{U} / \mathrm{L}$; GGT (gamma-glutamyl transpeptidase) $<65 \mathrm{U} / \mathrm{L}$; ALP (alkaline phosphatase) $<115 \mathrm{U} / \mathrm{L}$; total cholesterol $<190 \mathrm{mg} / \mathrm{dL}$; triglycerides $<140 \mathrm{mg} / \mathrm{dL}$; total bilirubin $<1.2 \mathrm{mg} / \mathrm{dL}$; glucose $110 \mathrm{mg} / \mathrm{dL}$.

$P$ value adjusted for the Bonferroni test. found in either serum leptin or TNF- $\alpha$ between the two groups (Table 2).

In the PBC group, there was a significant increase in serum adiponectin with advancing histological stage $(f=5.88$, $P=0.001$ ), whereas there was a negative correlation between adiponectin and BMI $\left(\mathrm{r}^{2}=0.061, P=0.01\right)$.

Logistic regression analysis, performed in patients with PBC, showed that higher adiponectin level was independently correlated to age (adjusted OR 1.043, 95\% CI 1.002-1.086, $P=0.042$ ), BMI (adjusted OR $0.379,95 \%$ CI $0.149-0.963$, $P=0.041$ ), Mayo score (adjusted OR 1.764, 95\% CI 1.1462.716, $P=0.042$ ), and gamma-glutamyl transpeptidase (GGT) (adjusted OR 0.340, 95\% CI 0.135-0.853, $P=0.022$ ) (Table 3).

\section{DISCUSSION}

The results of our study indicate that adiponectin, resistin, and leptin, but not TNF- $\alpha$, are significantly higher in the sera of PBC patients than in either NASH patients or healthy controls. In our PBC patients, only adiponectin was associated with histological progression and it correlated negatively with BMI. Moreover, logistic regression analysis revealed that adiponectin correlated independently with age, Mayo score, and GGT. These results prompt several considerations.

First of all, hypercholesterolemia is a clinical problem in PBC, but judging from preliminary studies (1-3), it should not be regarded as a risk factor for cardiovascular disease in PBC. The search for factors protecting against endothelial damage is still on, however. Our study paves the way to further research to demonstrate whether adiponectin has a key role in this sense. Serum adiponectin was found significantly higher than normal in 20 cirrhotic patients and it correlated with liver function impairment and altered hepatic hemodynamics (19). In another article, Tacke et al. compared 111 chronic liver disease patients (mostly cirrhotic with different etiology) and 226 healthy controls (20) and found adiponectin significantly elevated in cirrhotic patients, correlating with the stage of liver cirrhosis, liver cell injury, and biochemical markers of cholestasis (20). Interestingly, the same authors (20) found a 2- to 3 -fold increase in serum adiponectin in an experimental model of bile duct ligation. They monitored hepatic adiponectin gene expression in this experimental model, thereby confirming that the increase in serum adiponectin was due to decreased biliary secretion of adipose tissue-derived adiponectin, rather than due to a stimulation of hepatic production of adiponectin. In this light, because biliary secretion is involved in the clearance of adiponectin, progressive cholestasis may favor the intrahepatic accumulation of adiponectin. In this view, the increasing levels of this adipokine with the progression of the disease might be interpreted as an adaptative phenomenon to cholestasis. Moreover, as the progression of PBC is very slow (21), the accumulation of this hepatoprotective hormone could 

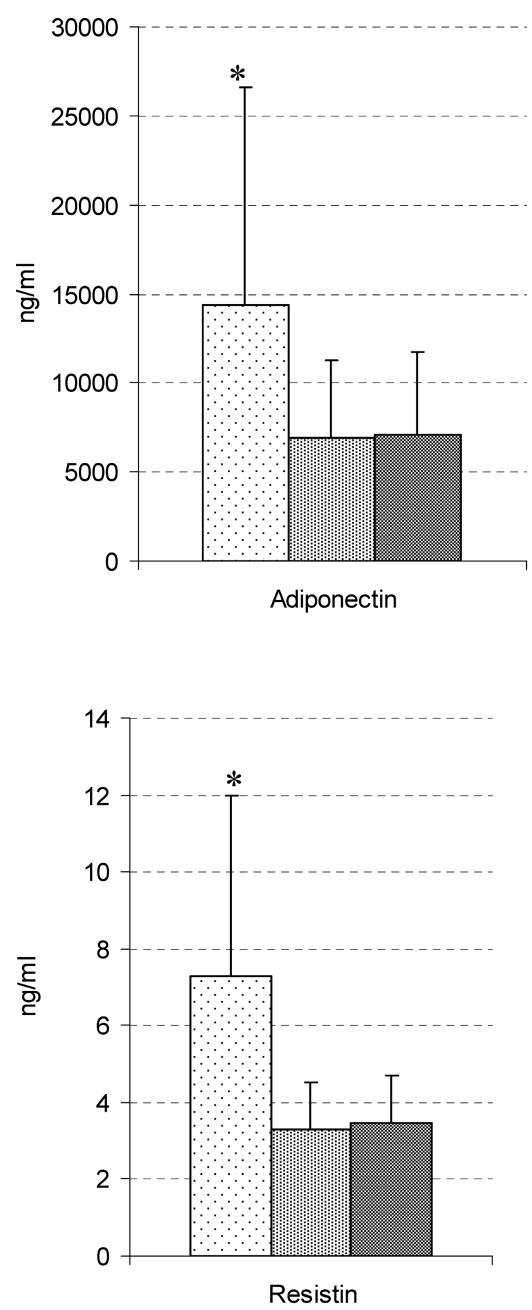
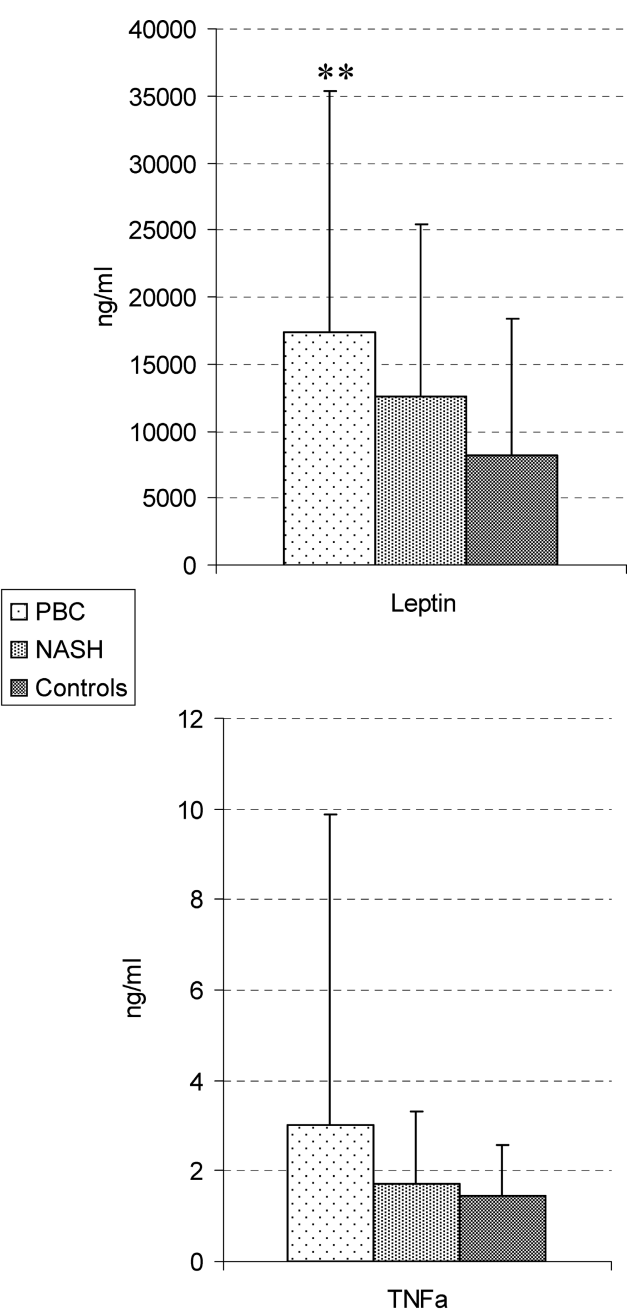

${ }^{*} \mathrm{PBC}$ vs $\mathrm{NASH} /$ controls $=P<0.05 ;{ }^{* *} \mathrm{PBC}$ vs controls $=P<0.05$

Figure 1. Serum levels of adipokines in PBC and NASH patients and healthy controls.

potentially contribute to the long natural history of this disease. This hypothesis needs further study, however, because the hepatoprotective role of adiponectin has only been established in experimental studies, not in humans $(22,23)$. Nevertheless, recent evidence convincingly demonstrated that adiponectin profoundly interacts with the immune/macrophage system and might be of relevance in many liver diseases (24).

The protective role of adiponectin in relation to the development of atherosclerosis is well known (25). The notion that plasma adiponectin concentrations are lower in patients with coronary artery disease supports the concept that adiponectin could somehow protect against atherosclerosis (26). Adiponectin modulates endothelial function and inhibits proliferation of vascular smooth muscle cells induced by growth factors (27). It also has an in vitro inhibitory effect on TNF- $\alpha$-induced monocyte adhesion and adhesion molecule expression (28). Adiponectin-deficient mice recently showed twice as much neointimal formation in response to external injury as wild-type mice (29).
The lower adiponectin levels in NASH patients compared to either PBC patients or controls confirm the results obtained in previous studies $(30,31)$, where adiponectin was inversely correlated with liver steatosis, but the correlation between adiponectin and insulin resistance and fibrosis has yet to be fully clarified. However, comparing the NASH subjects with a group of PBC patients matched for age, sex, and degree of liver fibrosis, adiponectin serum levels were still significantly higher in PBC than in NASH patients.

Serum leptin was found significantly higher in $\mathrm{PBC}$ than in either NASH cases or controls, thereby suggesting some intriguing hypotheses. In fact, studies performed in cirrhotic patients from different aetiologies have shown that serum leptin tends to rise in cirrhosis, especially in the early stages (32-35); but in this complex setting, the higher serum concentrations are probably due to this hormone's involvement in fibrogenesis (36-38), rather than due to atherosclerosic processes. Indeed, the association between leptin and coronary artery calcification was examined by Reilly et al. (39), who found an association between plasma leptin and coronary 
Table 2. Clinical Details of the Study Groups (Biochemical Parameters Are Expressed as Mean \pm SD)

\begin{tabular}{|c|c|c|c|}
\hline & $\mathrm{PBC}^{*}$ & NASH & $P$ Value \\
\hline Number & 30 & 30 & \\
\hline Age (yr) & $50.8 \pm 4.5$ & $49.9 \pm 3.7$ & NS \\
\hline BMI & $25.1 \pm 4.4$ & $24.5 \pm 2.8$ & NS \\
\hline AST (U/L) & $36.4 \pm 23.6$ & $32.9 \pm 13.1$ & NS \\
\hline ALT (U/L) & $48.8 \pm 40.7$ & $66.3 \pm 15.8$ & NS \\
\hline GGT (U/L) & $92.0 \pm 66.4$ & $86.9 \pm 14.8$ & NS \\
\hline $\operatorname{ALP}(\mathrm{U} / \mathrm{L})$ & $271.9 \pm 286.7$ & $86.6 \pm 33.3$ & 0.01 \\
\hline Total bilirubin $(\mu \mathrm{mol} / \mathrm{L})$ & $0.67 \pm 0.35$ & $0.88 \pm 0.31$ & NS \\
\hline Cholesterol (mg/dL) & $226.8 \pm 52.4$ & $221.7 \pm 39.7$ & NS \\
\hline Triglycerides (mg/dL) & $120.1 \pm 40.2$ & $146.2 \pm 79.1$ & NS \\
\hline Glucose $(\mathrm{mg} / \mathrm{dL})$ & $103.2 \pm 24.0$ & $82.2 \pm 7.7$ & 0.02 \\
\hline Adiponectin (ng/mL) & $11,493.1 \pm 7,005.7$ & $6,941.3 \pm 4,348.6$ & 0.04 \\
\hline Leptin $(\mathrm{ng} / \mathrm{mL})$ & $25,992.2 \pm 29,051.3$ & $12,529.8 \pm 12,835.8$ & NS \\
\hline Resistin (ng/mL) & $6.1 \pm 4.3$ & $3.3 \pm 1.2$ & 0.01 \\
\hline $\mathrm{TNF}-\alpha(\mathrm{pg} / \mathrm{mL})$ & $1.7 \pm 1.5$ & $1.7 \pm 1.6$ & NS \\
\hline \multicolumn{4}{|l|}{ Histological stage } \\
\hline I & - & - & \\
\hline II & 20 & 20 & \\
\hline III & 10 & 10 & \\
\hline IV & - & - & \\
\hline
\end{tabular}

Normal values: AST (aspartic aminotransferase) <35 U/L; ALT (alanine aminotransferase) <40 U/L; GGT (gamma-glutamyl transpeptidase) <65 U/L; ALP (alkaline phosphatase) $<115 \mathrm{U} / \mathrm{L}$; total cholesterol $<190 \mathrm{mg} / \mathrm{dL}$; triglycerides $<140 \mathrm{mg} / \mathrm{dL}$; total bilirubin $<1.2 \mathrm{mg} / \mathrm{dL}$; glucose $110 \mathrm{mg} / \mathrm{dL}$.

$P$ value adjusted for the Bonferroni test.

* This group is a part of the 137 PBC study group.

atherosclerosis in type 2 diabetes. Moreover, in a recent article by Singhal et al. (40), 294 healthy adolescents underwent brachial artery distensibility measurement; higher leptin levels were associated with impaired vascular function, irrespective of any metabolic or inflammatory conditions associated with obesity. The hypothesis that leptin has an independent influence on vessel health is supported by recent prospective observations that leptin is an independent risk factor for coronary events $(41,42)$. Paradoxically, these observations do not seem to apply to liver disease patients. In PBC patients, in particular, we failed to find any correlation between leptin and either BMI or severity of liver disease. Further studies are warranted, however, to investigate the effect of chronic hyperleptinemia on vascular function.
The same considerations apply to serum resistin concentration. Circulating resistin levels are increased in mouse models of obesity and in obese humans and are involved in the pathogenesis of diabetic complications (43). The source of resistin, however, is currently being debated, (44), and resistin release appears to be stimulated by inflammation, LPS (lipopolysaccharide), IL (interleukin)-6, hyperglicemia, and growth and gonadal hormones (43).

Finally, TNF- $\alpha$ revealed no differences between PBC patients and either NASH cases or healthy controls. TNF- $\alpha$ is a complex cytokine that may have numerous effects in cholestasis (45). In general, its levels tend to be higher in histologically more advanced stages than in early stages, but they decline under UDCA (ursodeoxycholic acid) therapy (46). All

Table 3. Multivariate Analysis of Risk Factors Associated to High Level of Adiponectin in PBC Patients

\begin{tabular}{|c|c|c|c|c|}
\hline \multirow[b]{2}{*}{ Variable } & \multirow[b]{2}{*}{ Adjusted OR } & \multicolumn{2}{|c|}{$95.0 \% \mathrm{CI}$ for Adjusted OR } & \multirow[b]{2}{*}{$P$ Value } \\
\hline & & Lower & Upper & \\
\hline Age (continuous variable) & 1.043 & 1.002 & 1.086 & 0.042 \\
\hline $\mathrm{BMI}(\geq 25.0 v s<25.0)$ & 0.379 & 0.149 & 0.963 & 0.041 \\
\hline Mayo score (continuous variable) & 1.764 & 1.146 & 2.716 & 0.010 \\
\hline Stage (continuous variable) & 1.422 & 0.869 & 2.326 & 0.161 \\
\hline AST (abnormal vs normal) & 1.634 & 0.548 & 4.877 & 0.379 \\
\hline ALT (abnormal vs normal) & 0.640 & 0.218 & 1.885 & 0.418 \\
\hline GGT (abnormal vs normal) & 0.340 & 0.135 & 0.853 & 0.022 \\
\hline ALP (abnormal vs normal) & 2.756 & 0.713 & 10.657 & 0.142 \\
\hline Total cholesterol (abnormal vs normal) & 1.440 & 0.472 & 4.389 & 0.522 \\
\hline Triglycerides (normal $v s$ abnormal) & 1.086 & 0.387 & 3.051 & 0.875 \\
\hline Total bilirubin (abnormal vs normal) & 1.108 & 0.303 & 4.047 & 0.877 \\
\hline Glucose (abnormal vs normal) & 1.619 & 0.598 & 4.386 & 0.343 \\
\hline
\end{tabular}

Normal values: AST (aspartic aminotransferase) <35 U/L; ALT (alanine aminotransferase) <40 U/L; GGT (gamma-glutamyl transpeptidase) <65 U/L; ALP (alkaline phosphatase) $<115 \mathrm{U} / \mathrm{L})$; total cholesterol $<190 \mathrm{mg} / \mathrm{dL}$; triglycerides $<140 \mathrm{mg} / \mathrm{dL}$; total bilirubin $<1.2 \mathrm{mg} / \mathrm{dL}$; glucose $110 \mathrm{mg} / \mathrm{dL}$. 
patients with PBC were on UDCA, so we could not expect to see any significant variation in TNF- $\alpha$ levels.

In conclusion, the high concentration of adiponectin seen in PBC patients suggests that it should be regarded as a likely protective factor against atherogenesis. The search for further factors should be encouraged.

\section{STUDY HIGHLIGHTS}

\section{What Is Current Knowledge}

- Hypercholesterolemia is a common finding in primary biliary cirrhosis (PBC), but the risk of cardiovascular events is not increased in respect to the general population.

- No putative protective factors have been studied specifically as yet in PBC.

\section{What Is New Here}

- Serum concentration of adiponectin, resistin, and leptin are significantly higher in PBC patients than in either NASH cases or healthy controls. Among the PBC patients, only adiponectin correlates positively with the disease progression and negatively with body mass in$\operatorname{dex}(\mathrm{BMI})$.

- Logistic regression analysis reveals that adiponectin correlates independently with age, BMI, Mayo score, and gamma-glutamyl transpeptidase.

- The high adiponectin concentration should be regarded as a possible protective factor against atherosclerosis.

Reprint requests and correspondence: Annarosa Floreani, Department of Surgical and Gastroenterological Sciences, University of Padova, Via Giustiniani, 2, 35128 Padova, Italy.

Received May 29, 2007; accepted February 19, 2008.

\section{REFERENCES}

1. Crippin JS, Lindor KD, Jorgensen R, et al. Hypercholesterolemia and atherosclerosis in primary biliary cirrhosis: What is the risk? Hepatology 1992;15:858-62.

2. Longo M, Crosignani A, Battezzati PM, et al. Hyperlipidaemic state and cardiovascular risk in primary biliary cirrhosis. Gut 2002;51:265-9.

3. Allocca M, Crosignani A, Gritti A, et al. Hypercholesterolaemia is not associated with early atherosclerotic lesions in primary biliary cirrhosis. Gut 2006;55:1795800 .

4. Szmitko PE, Teoh H, Stewart DJ, et al. Adiponectin and cardiovascular disease. Am J Physiol Heart Circ Physiol 2006;292:H1655-63.

5. Kershaw EE, Flier JS. Adipose tissue as an endocrine organ. J Clin Endocrinol Metab 2004;89:2548-56.

6. Diez JJ, Iglesias P. The role of the novel adipocyte-derived hormone adiponectin in human disease. Eur J Endocrinol 2003;148:293-300.
7. Maahs DM, Ogden LG, Kinney GL, et al. Low plasma adiponectin levels predict progression of coronary artery calcification. Circulation 2005;111:747-53.

8. Friedman JM, Halaas JL. Leptin and the regulation of body weight in mammals. Nature 1998;395:763-70.

9. Flier JS. Clinical review 94: What's in a name? In search of leptin's physiologic role. J Clin Endocrinol Metab 1998;83:1407-13.

10. Steppan CM, Bailey ST, Bhat S, et al. The hormone resistin links obesity to diabetes. Nature 2001;409:307-12.

11. Banerjee RR, Lazar MA. Resistin: Molecular history and prognosis. J Mol Med 2003;81:218-26.

12. Ruan H, Hacohen N, Golub TR, et al. Tumor necrosis factoralpha suppresses adipocyte-specific genes and activates expression of preadipocyte genes in 3T3-L1 adipocytes: Nuclear factor-kappaB activation by TNF-alpha is obligatory. Diabetes 2002;51:1319-36.

13. Ruan H, Lodish HF. Insulin resistance in adipose tissue: Direct and indirect effects of tumor necrosis factor-alpha. Cytokine Growth Factor Rev 2003;14:447-55.

14. Tilg H, Hotamisligil GH. Nonalcoholic fatty liver disease: Cytokine-adipokine interplay and regulation of insulin resistance. Gastroenterology 2006;131:934-45.

15. Dickson ER, Grambsch PM, Fleming TR, et al. Prognosis in primary biliary cirrhosis: A model for decision making. Hepatology 1989;10:1-7.

16. Expert Panel on Detection Evaluation and Treatment of High Cholesterol in Adults. Executive summary of the third report of the National Cholesterol Education Program (NCEP) expert panel on detection, evaluation, and treatment of high blood cholesterol in adults (Adult Treatment Panel III). JAMA 2001;285:2486-97.

17. Brunt EM, Janney CG, Di Bisceglie AM, et al. Nonalcoholic steatohepatitis: A proposal for grading and staging the histological lesions. Am J Gastroenterol 1999;94:2467-74.

18. Matthews DR, Hosker JP, Rudenski AS, et al. Homeostasis model assessment: Insulin resistance and beta-cell function from plasma fasting glucose and insulin concentrations in man. Diabetologia 1985;28:412-9.

19. Tietge UJ, Boker KH, Manns MP, et al. Elevated circulating adiponectin levels in liver cirrhosis are associated with reduced liver function and altered hepatic hemodynamics. Am J Physiol Endocrinol Metab 2004;287:E82-9.

20. Tacke F, Wustefeld T, Horn R, et al. High adiponectin in chronic liver disease and cholestasis suggests biliary route of adiponectin excretion in vivo. J Hepatol 2005;42:666-73.

21. Pares A, Rodes J. Natural history of primary biliary cirrhosis. Clin Liver Dis 2003;7:779-94.

22. Kamada Y, Tamura S, Kiso S, et al. Enhanced carbon tetrachloride-induced liver fibrosis in mice lacking adiponectin. Gastroenterology 2003;125:1796-807.

23. Masaki T, Chiba S, Tatsukawa H, et al. Adiponectin protects LPS-induced liver injury through modulation of TNF-alpha in kk-Ay obese mice. Hepatology 2004;40:177-84.

24. Tilg H, Kaser A, Moschen AR. How to modulate inflammatory cytokines in liver diseases. Liver Int 2006;26:1029-39.

25. Ukkola O, Santaniemi M. Adiponectin: A link between excess adiposity and associated comorbidities? J Mol Med 2002;80:696-702.

26. Ouchi N, Kihara S, Arita Y, et al. Novel modulator for endothelial adhesion molecules: Adipocyte-derived plasma protein adiponectin. Circulation 1999;100:2473-6.

27. Matsuzawa Y, Funahashi T, Nakamura T. Molecular mechanism of metabolic syndrome X: Contribution of adipocytokines adipocyte-derived bioactive substances. Ann N Y Acad Sci 1999;894:146-54. 
28. Ouchi N, Kihara S, Arita Y, et al. Adiponectin and adipocyte-derived plasma protein inhibits endothelian NFkappaB through a cAMP-dependent pathway. Circulation 2000;102:1296-301.

29. Kubota N, Terauchi Y, Kubota T, et al. Pioglitazone ameliorates insulin resistance and diabetes by both adiponectin-dependent and -independent pathways. J Biol Chem 2006;281:8748-55.

30. Musso G, Gambino R, Durazzo M, et al. Adipokines in NASH: Postprandial lipid metabolism as a link between adiponectin and liver disease. Hepatology 2005;42:117583.

31. Hui JM, Hodge A, Farrell GC, et al. Beyond insulin resistance in NASH: TNF-alpha or adiponectin? Hepatology 2004:40:46-54

32. Bugianesi E, Pagotto U, Manini R, et al. Plasma adiponectin in non-alcoholic fatty liver is related to hepatic insulin resistance and hepatic fat content, not to liver disease severity. J Clin Endocrinol Metal 2005;90:3498-504.

33. Testa R, Franceschini R, Giannini E, et al. Serum leptin levels in patients with chronic viral hepatitis or liver cirrhosis. J Hepatol 2000;33:33-7.

34. Comlekci A, Akpinar H, Yesil S, et al. Serum leptin levels in patients with liver cirrhosis and chronic viral hepatitis. Scand J Gastroenterol 2003;38:779-86.

35. Lin SY, Wang YY, Sheu WH. Increased serum leptin concentrations correlate with soluble tumour necrosis factor receptor levels in patients with cirrhosis. Clin Endocrinol 2002;57:805-11.

36. Frank S, Stallmeyer B, Kampfer H, et al. Leptin enhances wound re-epithelization and constitutes a direct function of leptin in skin repair. J Clin Invest 2000;106:501-9.

37. Ring BD, Scully S, Davis CR, et al. Systemically and tipically administered leptin both accelerate wound healing in diabetic ob/ob mice. Endocrinology 2000;141:446-9.

38. Ikejima $\mathrm{K}$, Honda $\mathrm{H}$, Yoshikawa $\mathrm{M}$, et al. Leptin augments inflammatory and profibrogenic responses in the murine liver induced by hepatotoxic chemicals. Hepatology 2001;34:288-97.

39. Reilly MP, Iqbal N, Schutta $M$, et al. Plasma leptin levels are associated with coronary atherosclerosis in type 2 diabetes. J Clin Endocrinol Metab 2004;89: 3872-8
40. Singhal A, Farooqi IS, Cole TJ, et al. Influence of leptin on arterial distensibility: A novel link between obesity and cardiovascular disease? Circulation 2002;106:1919-24.

41. Soderberg S, Arhen B, Jansson JH, et al. Leptin is associated with increased risk of myocardial infarction. J Intern Med 1999;246:409-18.

42. Wallace AM, McMahon AD, Packard CJ, et al. Plasma leptin and the risk of cardiovascular disease in the West of Scotland Coronary Prevention Study (WOSCOPS). Circulation 2001;104:3052-6.

43. Guzik TJ, Mangalat D, Korbut R. Adipocytokines - a novel link between inflammation and vascular function? J Physiol Pharmacol 2006;57:505-28.

44. Wasim H, Al-Daqhri NM, Chetty R, et al. Relationship of serum adiponectin and resistin to glucose intolerance and fat topography in South Asians. Cardiovasc Diabetol 2006;2:510 .

45. Jones A, Selby PJ, Viner C, et al Tumour necrosis factor, cholestatic jaundice and chronic liver disease. Gut 1990;31:938-9.

46. Neumann M, Angulo P, Malkiewicz P, et al. Tumour necrosis factor-a and transforming growth factor-b reflect severity of liver damage in primary biliary cirrhosis. J Gastroenterol Hepatol 2002;17:196-202.

\section{CONFLICT OF INTEREST}

Guarantor of the article: Marilena Durazzo.

Specific author contributions: All authors share some degree of responsibility for the article. Annarosa Floreani: designed the research and wrote the article; A. Variola, G. Niro, A. Premoli, M. Cassader, and E. Rosa Rizzotto: performed the research; V. Baldo: analyzed the data; G. Musso: contributed new agents; S. Bo: contributed analytic tools; F. Ferrara and D. Caroli: collected the clinical data; and Marilena Durazzo: performed an appropriate process for reviewing the accuracy of the reported results.

Financial support: This work was partially supported by a ministerial grant (MIUR ex 60\%).

Potential competing interests: None. 